\title{
As práticas de conluio nas licitações públicas à luz da teoria dos jogos
}

Francisco Campos*

Resumo: O presente artigo avalia se as regras inseridas nos procedimentos licitatórios são eficazes no combate às práticas de conluios e se geram incentivos para os licitantes apresentarem propostas verdadeiras (aquelas que não extraem todo excedente econômico). Em vista disso, utiliza-se a teoria dos jogos e a teoria econômica dos cartéis como instrumentos de análise. As principais conclusões do artigo são que os incentivos econômicos vislumbrados pelos agentes e a limitada eficácia dos instrumentos licitatórios relativos aos procedimentos de divulgação, julgamento e desclassificação das propostas não evitam as práticas de conluio nas aquisições do setor público, exceto no pregão eletrônico com muitos participantes, onde a probabilidade de êxito das práticas de conluio são reduzidas.

Palavras-chave: Licitações Públicas, Conluios, Teoria dos Jogos.

Abstract: The present article analyzes as the cartels act in the public administration and if the inserted rules in the biddings are efficient in the combat to the practical ones of collusions and generate incentives them bidders to present true proposals (those that they do not extract all exceeding economic). In sight of this, it is used games theory and the economic theory of the cartels as analysis instruments. The main conclusions of the article are that the economic incentives glimpsed by the agents and the limited effectiveness of the relative instruments of bidding to the spreading procedures, judgment and declassification of the proposals do not prevent the practical ones of collusion in the acquisitions of the public sector, except in the electronic biddings with many participants, where the probability of success of the practical ones of collusion is reduced.

Keywords: Bidding, Collusions, Game Theory.

JEL Classification: D43; D44; D82; H57.

\section{Introdução}

Assim como nos gastos privados, a eficiência do gasto público pressupõe que numa aquisição de bens/serviços se esteja pagando o valor efetivo da mercadoria, ou seja, aquele preço que se iguala

* Mestre em Economia pelo CAEN/UFC. E-mail: camposfao@gmail.com 
aos custos marginais. Mas, essa situação trata-se de uma economia de concorrência perfeita, que de fato é pouco praticada (restrita a alguns mercados). Fora dessa lógica de mercado de concorrência perfeita, a eficiência do gasto público, considerando que a compra/ aquisição seja oportuna e necessária, consiste na ausência de qualquer tipo de desperdício na sua aquisição ou contratação ou ainda no seu menor custo possível de financiamento, no caso de existência de déficit público.

Contudo, uma situação comum na administração pública é a formação de cartel/conluio para a prática de sobrepreço nas licitações públicas, principalmente quando se refere a um mercado com poucos fornecedores, onde há maiores facilidades de se coordenar um acordo. Além dessa imperfeição de mercado, os procedimentos normativos das aquisições (Lei no 8.666/93 e 10.520/02) e a legislação específica antitrustes (comandada pela Lei $n^{\circ} 8.884 / 94$ ) não se mostram suficientemente adequados para evitar as atuações dos cartéis/conluio, exceto no caso de pregão eletrônico com muitas empresas participantes, como se verá adiante. Tanto que, recentemente, o Governo Federal encaminhou ao Congresso Nacional o Projeto de Lei $n^{\circ}$ 7709/2007 no sentido de reformar a Lei $n^{\circ} 8.666 / 93$ e ampliar o uso do pregão, visto que a cada ano o volume de recursos decorrentes da ineficiência dos gastos atrelada a alguma prática de conluio se torna exorbitante. Pelas estimativas da Secretaria de Defesa Econômica, do Ministério da Justiça, para compras e aquisições anuais da ordem de $R \$ 300$ bilhões, o prejuízo gira entre $R \$ 25$ a $R \$ 40$ bilhões (site www.mj.gov.br - comunicado de 30/05/2007).

As evidências das práticas de cartéis nas compras públicas podem ser vista na mídia, as quais constantemente são noticiadas em relatos de alguma operação policial, tais como as operações da Polícia Federal: Operação Guabiru (17/05/04), Operação Vampiro (19/05/04), Operação Sentinela (02/12/04), Operação Sanguessuga (04/05/2006), Operação Carta Marcada (02/05/2006), Operação Fox (18/07/2006) entre outras.

São freqüentes, ainda, as notícias que os gerentes das áreas de prestação de serviços das empresas se reúnem, e os grandes dividem o mercado. Às vezes, os pequenos ganham. Como é uma informação de conhecimento comum entre as empresas, o grande interesse dos pequenos é receber comissão para não participar, ou receber comissão para dar cobertura aos grandes.

Por isso, o objetivo do presente artigo consiste em analisar como os cartéis atuam na administração pública e se as regras constantes dos procedimentos licitatórios são eficazes no combate às práticas de 
conluios e nos incentivos dos licitantes a apresentarem propostas verdadeiras (aquelas que não extraem excedente econômico). Utilizase a teoria dos jogos e a teoria econômica dos cartéis (a microeconomia da concorrência imperfeita) como instrumentos de análise, visto que essas teorias captam as interações e os incentivos econômicos inerentes ao processo decisório de provimento de bens e formação de preços.

Outro interesse do estudo que se segue é a possibilidade de ampliar o campo de análise do setor público por meio da teoria dos jogos. O setor público convive com diversos problemas de incentivos e de assimetria de informações nos quais geram atividades econômicas ilícitas e ineficientes, cujas soluções impactam a vida dos indivíduos por meio de carga tributária elevada e distorciva, déficit público, morosidade judiciária, realocações indevidas de gastos entre outras conseqüências diretas.

Do ponto de vista teórico, faz-se uma breve contextualização dos aspectos da teoria dos jogos que serão considerados na análise das práticas de conluio nas licitações públicas, bem como caracteriza-se a atuação dos cartéis/conluios. Sob a ótica institucional, abordada-se as principais regras inseridas nos procedimentos utilizados pela administração pública na aquisição de bens se serviços, na forma da Lei de Licitações $n^{\circ} 8.666 / 93$ e $n^{\circ} 10.520 / 02$. Posteriormente, segue a análise propriamente dita, na forma de respostas às indagações que serão levantadas em termo de título sobre o objeto em foco, tais como: há incentivo para uma empresa apresentar uma proposta verdadeira? $\mathrm{Na}$ medida do possível, essa técnica será usada no presente trabalho.

\section{Considerações Teóricas e Institucionais}

\section{a) Teoria do Jogos}

Jogo é toda a situação em que existem duas ou mais entidades em uma posição em que as ações de uma interferem nos resultados de outra. Já a teoria dos jogos consiste em um instrumental matemático para modelar as interações de dois ou mais agentes numa tomada de decisão. A teoria dos jogos estuda o processo de decisão estratégica onde as ações das outras pessoas revelam algo sobre o que um agente (ou vários agentes) sabe, com isso, há o uso desta informação para orientar as próprias ações desses agentes. Isto é, há uma interdependência estratégica, principalmente quando se trata de jogos não cooperativos. Mesmo nesse tipo de jogo, o bem estar individual não depende só das suas ações, mas, também das ações de outros indivíduos. De fato, as inter-relações permitem uma combinação de informações 
extraídas com as que o agente tem acerca da questão e o uso desse conjunto de informações para definir dispositivos estratégicos numa tomada de decisão.

A teoria dos jogos é usada para se estudar assuntos tais como leilões, negociações empresariais e comerciais, evolução genética, comportamentos políticos, práticas de análise econômica de concorrência e determinação de preços, política de comércio internacional, externalidades entre outros assuntos relevantes.

Os jogos na forma normal consistem na apresentação de um conjunto de jogadores, um conjunto de estratégias para cada jogador e um conjunto de resultado (payoffs) do jogo, que descreve a utilidade de cada jogador quando um dado conjunto de estratégias é escolhido. É apresentado por meio de matrizes, onde constam os elementos retromencionados.

Há duas hipóteses básicas nesses jogos, que são a racionalidade dos jogadores (preferem mais a menos e maximizam sua utilidade) e o conhecimento comum (commom knowledge). Nesta última, cada jogador conhece os resultados e as estratégias de todos os jogadores. Assim, todos os jogadores conhecem a estrutura do jogo, conhecem que seus rivais sabem disso, conhecem que seus rivais sabem que eles sabem disso.

A solução do jogo de estratégias puras ${ }^{1}$ ocorre por meio da verificação da dominância das estratégias ou via Equilíbrio de Nash. No primeiro caso, procura-se uma estratégia dominante (pode se chegar a ela por meio da eliminação iterada das estratégias dominadas), aquela que é melhor para o jogador independentemente da escolha do outro jogador, assim, o jogador racional sempre jogará a estratégia dominante. No Equilíbrio de Nash, ${ }^{2}$ que trata da estratégia que garante o melhor resultado independentemente das escolhas dos outros jogadores, não há incentivo a desvios caso as escolhas dos outros jogadores sejam mantidas.

Agora, ilustra-se os conceitos abordados acima por meio de um jogo simultâneo ${ }^{3}$ bastante conhecido na literatura da teoria dos jogos,

1 Existem os jogos de estratégias mistas que são aqueles onde se atribui probabilidades às jogadas para encontrar o equilíbrio estável. Nas estratégias puras, as escolhas são determinísticas e nas estratégias mistas as escolhas são randomizadas.

2 Principalmente por meio de estratégias mistas, pois caso um jogo não tenha um ou tenha mais que Equilíbrio de Nash em estratégias puras, o equilíbrio encontrado em estratégia mista será estável.

3 Nos jogos simultâneos cada jogador ignora as decisões dos demais no momento em que toma a sua própria decisão (os jogadores se movem somente uma vez e ao mesmo tempo), em contrapartida, os jogos seqüenciais o jogador imagina as respostas futuras dos outros jogadores e usa-as para calcular qual é o seu melhor lance. 
que trata da solução de um conflito chamado de "Dilema dos Prisioneiros", no caso não repetido. Nesse jogo dois prisioneiros são instados a confessar um crime por meio de um sistema de incentivo, embora o melhor resultado fosse ambos não confessarem. Eis o sistema de incentivo implementado: i) o prisioneiro pode escolher entre confessar e não confessar. ii) se apenas um confessa ele é solto e o outro é condenado a seis meses de prisão. Se ambos negarem, cada um pega um mês de prisão. Se ambos confessarem a pena é de três meses para cada um.

Dilema dos Prisioneiros

\begin{tabular}{|l|l|l|l|}
\cline { 3 - 4 } \multicolumn{2}{c|}{} & \multicolumn{2}{c|}{ Prisioneiro 2 } \\
\cline { 3 - 4 } \multicolumn{2}{c|}{ Prisioneiro 1 1} & Confessa & Não Confessa \\
\cline { 2 - 4 } & Confessa & $-3 ;-3$ & $0 ;-6$ \\
\cline { 2 - 4 } & Não Confessa & $-6 ; 0$ & $-1 ;-1$ \\
\hline
\end{tabular}

Os payoffs são negativos porque se trata de tempo na prisão, ou seja, uma desutilidade para um agente racional. No caso acima, há uma estratégia dominante para cada jogador, pois é sempre melhor confessar, não importando o que o outro jogador escolha. Diante disso, a solução do jogo é (confessa, confessa). Vale ressaltar que esse resultado decorre do fato dos dois prisioneiros não poderem se comunicar, pois eles foram colocados em celas separadas. Caso houvesse comunicação entre eles, os resultados dependeriam da possibilidade de estabelecimento de compromissos que pudessem ser garantidos por meio de ameaças críveis para evitar trapaças. Uma ameaça crível é aquela possível de ser realizada, mesmo que o agente ameaçador incorra em prejuízos no estágio seguinte. Por exemplo, cobrar preços abaixo dos custos e fazer o jogador que não honrou o acordo perder mercado.

Um ramo da teoria dos jogos é o desenho mecanismo, usado quando há problemas de informação privada (incompleta) nos modelos de principal-agente, como forma de prover incentivos para que a parte mais informada não se desvie dos objetivos avençados (direção desejada). Os modelos de principal-agente tratam de situação onde existe informação ou ação cuja utilização por parte do agente pode gerar vantagens numa relação de contrato/negócio. Quando se refere a uma ação diz-se que é problema de moral hazard (por exemplo no contrato de seguro, não se sabe ao certo do comportamento do segurado, que pode agir de forma a facilitar a ocorrência do sinistro), 
quando for uma informação escondida, tem-se um problema de seleção adversa (por exemplo há dois tipos de agentes e a dificuldade de distingui-los leva a uma seleção adversa, no qual pode gerar disfunções econômicas. Uma ilustração clássica refere-se ao mercado de carros usados: usado de boa qualidade e usado de má qualidade. As sinalizações (emissão de um sinal por parte do agente ou pelo principal) são remédios contra esses problemas. ${ }^{4}$

Vale ressaltar que, em vista do presente trabalho se referir a licitações, nosso interesse será no caso no qual o principal toma a iniciativa de propor regras de forma a reduzir o rendimento da informação do agente ou fazer com que ele revele seu tipo.

Uma das aplicações dos modelos de desenho de mecanismo são os leilões, que podem ser conceituados como um mecanismo de mercado para equilibrar a oferta e a demanda. Os leilões são do tipo selado (envelope fechado) e os abertos (lances públicos); e os mais conhecidos são os de primeiro preço, onde o lance maior ganha e paga o valor desse lance, e o de segundo preço, o lance mais alto ganha mais paga o valor do segundo lance mais alto.

Pode-se inferir que uma licitação pública para aquisição de um bem segue a lógica de um leilão selado de primeiro preço, mas o vencedor é aquele que apresenta o valor mais baixo. Além disso, a licitação é um mecanismo que permite que os licitantes apresentem suas propostas e a administração escolha aquela que for mais vantajosa.

Visto da ótica do setor público, as aquisições de bens por esse setor consistem em um jogo no qual reflete uma situação com apenas um vencedor para cada jogo, isto é, não há um equilíbrio na forma em que todos os jogadores permanecem fornecendo produto para aquele demandante do setor público, embora com quantidades e resultados diferentes. Ademais, não é um jogo de soma zero, pois o lucro do vencedor não é necessariamente do tamanho da perda do vencido.

b) Cartel e Conluio

O cartel consiste de um grupo de ofertadores que fizeram um acordo explícito para limitar competição entre eles em seu próprio benefício. O objetivo é atuar como se fosse um monopólio, mas enquanto no monopólio a decisão cabe apenas a um produtor, o cartel consiste de uma associação voluntária de tomadores de decisão, cada qual consciente que o seu lucro depende do comportamento

4 Exemplos de sinalização: i)garantia adicional dada pelas fábricas para sinalizar que o seu produto tem qualidade e diferenciar daqueles de menor qualidade; ii)distribuição de dividendos no sentido de mostrar que a empresa se enquadra no bom cenário; iii) no mercado de trabalho, usar o nível educacional para sinalizar maior produtividade. 
do todos os ofertadores da indústria. Portanto envolve muito mais que uma simples definição do nível de preço e quantidade maximizante do lucro.

Os acordos surgem quando as firmas percebem a inconsistência do processo concorrencial em que estão inseridas e o fato que a interação entre elas de forma cooperativa pode levar à obtenção de uma ótima de lucratividade. A Interdependência de suas ações levam a um comportamento estratégico único permitindo à maximização conjunta de lucros.

Um aspecto importante do cartel é o seu gerenciamento, que deve se preocupar com três questões fundamentais: a alocação da produção entre os membros, a alocação do lucro do cartel entre os membros e o policiamento do acordo de cartel. ${ }^{5}$ Vale salientar que essas questões não são independentes entre si, daí a sua complexidade.

Em muitos países, a legislação interna não permite acordos colusivos, por isso, o cartel não pode ir ao tribunal exigir o cumprimento do acordo entre os membros. As atividades são escondidas para evitar perseguição. Os acordos colusivos entre países são permitidos (exemplo: OPEP), mas não são legalmente exigido o seu cumprimento. Como resultado, os acordos de cartéis deveriam ser sempre self-enforcing (auto cumprimento) e forward-looking e não envolver ameaças não críveis (BIERMAN; FERNANDEZ, 1998).

Os cartéis formais são aqueles em que as empresas estabelecem comunicação explícita ou contato direto, combinando preços ou regras de comportamento. De outro modo, quando a coordenação de preços ou ações é fruto da racionalidade econômica, as empresas seguem regras tácitas, que não foram combinadas explicitamente, ou seja, decorrentes da vivência na indústria e do aprendizado. Nesse caso, chama-se de cartéis tácitos, também conhecido na literatura econômica como "conluio tácito".

Nos casos de licitação pública, os acordos existentes entre licitantes tipifica-se também como cartel/conluio, conhecida como fraude em licitação pública. Esta consiste, simplesmente, do ponto de vista do direito antitruste, na coordenação entre empresas participantes de uma licitação pública, no sentido de prejudicar o objetivo do procedimento licitatório de obtenção de preços mais favoráveis para o licitante. Por exemplo, no caso de uma licitação de venda de um produto, as empresas podem agir de modo concertado para que se

5 Um bom exemplo da importância do policiamento do cumprimento do acordo, refere-se ao leilão de objetos onde, ex-ante, houve um conluio para baixar o preço reserva (o preço mínimo para fins venda). Neste caso, todos participam do leilão, mas nenhum apresenta oferta, uns ficam vigiando o outro. Ao leiloeiro resta cancelar ou baixar o preço reserva. 
determine qual delas apresentará o menor preço. Outra forma de fraudar esse tipo de procedimento é estabelecer um revezamento das empresas que irão vencer determinadas licitações ou ofertas públicas, pré-estabelecendo as ofertas que as empresas participantes e incluídas no esquema realizarão. ${ }^{6}$

Para o presente artigo, adota-se duas linhas de raciocínio sobre cartéis, primeiro cartel será sinônimo de conluio e segundo não haverá preocupação em distinguir entre conluio formal e tácito, pois conluio formal depende de contrato entre seus membros, mas um contrato que não tem eficácia legal também não faz muito sentido. No caso de conluio tácito será usado de uma forma geral representando qualquer acordo entre licitantes no que tange à combinação de estratégia de participação em licitações públicas com o sentido de obter vantagens (definir faixa de mercado, evitar entrada de concorrente, definir preço e obter excedente) ao arrepio da lei. ${ }^{7}$

Em termos de setor público, os conluios possuem configurações nas quais os preços combinados aparecem em pelo menos quatro variedades: fixação de preços de determinada proposta, divisão de uma proposta entre vários fornecedores, divisão de regiões geográficas entre fornecedores para gerar monopólios locais, e divisão dos órgãos do governo entre fornecedores novamente criando monopólios ou oligopólios (Ver KLITGAARD, 1994). Mas há de se observar que existem práticas colusivas no âmbito da administração pública que a divisão de mercado se ajusta apenas para objetos diferentes (pelo menos em termos de datas de licitação), visto que normalmente o parcelamento de um mesmo objeto é proibido pela Lei de Licitação.

Os indicadores de possíveis conluios são:

1. preços propostos maiores que os valores de mercado.

6 Existe caso de fraude, principalmente na modalidade convite, onde há apenas uma empresa e as outras duas somente existente no papel - contabilmente.

7 Pode ser encontrada uma definição de cartel como um acordo, tanto formal quanto tácito entre concorrentes, uma idéia que está presente na forma legal, mas que parece equivocada do ponto de vista econômico. Segundo Tirole, J. (1988): 'Colusão Tácita' não precisa envolver nenhuma 'colusão' no sentido legal, e particularmente envolve a não comunicação entre as partes. $\mathrm{O}$ acordo é referido como colusão tácita somente porque o resultado alcançado (em termos de conjunto de preços ou quantidades produzidas, por exemplo) pode ser bem parecido com os alcançados através da colusão explícita ou mesmo de um cartel oficial. Um melhor termo sob uma perspectiva legal deveria ser 'coordenação tácita'”). Importante notar, então, que a diferença básica entre cartel e o conluio tácito não está relacionada com seus resultados (desempenho em termos de preços e quantidades ofertadas), e sim, com o fato de que no conluio tácito não há comunicação direta entre os participantes, sendo que a conduta das firmas é conseqüência da racionalidade econômica dos agentes, que utilizam as características estruturais e instrumentos do mercado facilitadoras dessa prática. 
2. provas de que a mesma pessoa preparou todas as propostas.

3. padrão de rodízio entre concorrentes vencedores.

Como já mencionado acima, um conluio está sempre sob ameaça de seus lucros monopolistas serem atrativos para uma ou mais firmas entrarem ou romperem a formação, fazerem uma proposta inferior e embolsarem grandes lucros.

c) Aspectos econômicos e institucionais da licitação pública

Nas aquisições de bens e serviços, a entidade pública atua como um agente econômico qualquer, mas pelo fato de ser um grande comprador (em termos consolidado a administração pública brasileira faz aquisições anual de $\mathrm{R} \$ 300$ bilhões), ela impõe, de certa forma, as suas regras licitatórias que visam atender princípios constitucionais (publicidade, impessoalidade, legalidade, moralidade e eficiência) e possibilitar de forma isonômica a aquisição/contratação mais vantajosa para a administração pública à luz do que ela dispõe a pagar.

Durante a realização de um procedimento licitatório, quem decide se aceita ou não as condições dos licitantes é a entidade promotora do evento. Por isso mesmo, as normas licitatórias (Lei n ${ }^{\circ}$ 8.666/93 e Lei $\mathrm{n}^{\mathrm{O}}$ 10.520/02) indicam o caminho a ser, obrigatoriamente, seguido por todos os administradores públicos. Neste artigo a medida que for citado um instrumento ou procedimento constante da referida Lei, será apresentado em nota o significado de alguns deles. Contudo, cabe, a priori, referenciarmos os seguintes preceitos da Lei, em vista da sua similaridade com as condições seguidas pelos outros agentes da economia:

a) restrição orçamentária, visto que somente poderá haver licitação se houver orçamento detalhado em planilhas que expressem a composição de todos os seus custos unitários e previsão de recursos orçamentários que assegurem o pagamento das obrigações (ver artigos $7^{\circ}, 14^{\circ}$ e 40 ).

b) as compras, sempre que possível, deverão submeter-se às condições de aquisição e pagamento semelhantes às do setor privado e balizar-se pelos preços praticados no âmbito dos órgãos e entidades da Administração Pública (art. 15). As principais modalidades de licitação são convite, tomada de preços, concorrência e pregão, sendo utilizado prepoderantemente o critério de menor preço para a escolha do vencedor do certame licitatório (A Lei ainda prever outros critérios de julgamento que são a técnica e preço e melhor técnica, mas que são pouco utilizadas). As modalidades são definidas de acordo com o valor da estimativa da licitação e/ou com base numa imposição regulamentar, no caso do pregão. Além disso, 
a concorrência pode ser usada independentemente do valor e a tomada de preços pode ser usada mesmo que o valor seja de convite. Segue abaixo quadro definindo como deve ser a escolha da modalidade da licitação, com base no valor estimado:

Quadro 1. Critério de escolha da modalidade licitatória

\begin{tabular}{|l|l|}
\hline \multicolumn{1}{|c|}{ Modalidade } & \multicolumn{1}{c|}{ Fator para escolha da modalidade } \\
\hline Concorrência & $\begin{array}{l}\text { - Obras/Serviços de Engenharia: }>\mathrm{R} \$ 1.500 .000,00 \\
- \text { Compras e outros serviços: }>\mathrm{R} \$ 650.000,00\end{array}$ \\
\hline Tomada de Preços & - Obras/Serviços de Engenharia: $>\mathrm{R} \$ 150.000,00 \mathrm{e}<\mathrm{R} \$ 1.500 .000,00$ \\
& - Compras e outros serviços: $>\mathrm{R} \$ 80.000,00 \mathrm{e}<\mathrm{R} \$ 650.000,00$ \\
\hline Convite & - Obras/Serviços de Engenharia: $>\mathrm{R} \$ 15.000,00 \mathrm{e}<\mathrm{R} \$ 150.000,00$ \\
& - Compras e outros serviços: $>\mathrm{R} \$ 8.000,00 \mathrm{e}<\mathrm{R} \$ 80.000,00$ \\
\hline Pregão & Preferencial sobre as outras modalidades. Ou seja, o Pregão é prioritário. \\
\hline
\end{tabular}

Um dos pilares da licitação eficiente consiste na estimativa do valor do objeto ou serviço licitado, pois ela dará sustentação ao processo de julgamento das propostas apresentadas. Essa estimativa não é divulgada para os licitantes, embora a Lei de Licitação, art. 40, inciso X, permite (mas não obriga) a divulgação do valor máximo que a administração está disposta a pagar. Surgem duas observações a esse respeito, primeiro o valor máximo não implica que seja o valor estimado, segundo a divulgação antecipada do valor máximo incentivaria a prática de cartel.

A priori, não divulgar o valor estimado da licitação gera incentivos para que os concorrentes apresentem suas propostas de preços verdadeiras (ou seja, aquela que efetivamente representa seus custos e a margem de remuneração adequada para o negócio), visto que todos correm o risco de perderem a licitação. Adiante será mostrado que, de fato, os licitantes experientes têm idéia do valor estimado, principalmente no caso de obras e serviços de engenharia, e o máximo que a administração está disposta a pagar.

Outro pilar econômico da licitação (no sentido da economia da informação) refere-se à divulgação do edital da licitação, que será de acordo com a modalidade. Quanto maior a ampliação da divulgação maior a possibilidade de ampliação da competividade e a obtenção de melhores preços. Mas não há uma garantia para isso, pois o jogo licitatório cria incentivos para que as empresas apresentem propostas infladas. Com isso, a divulgação somente tem eficácia se combinada com outras regras, tais como aquelas do pregão eletrônico, onde as informações são incompletas e imperfeitas. Vale salientar que nos jogos de informação incompleta, o jogador somente conhece o seu payoff, ou seja ele não detém toda a informação para escolher sua 
jogada e nos jogos de informação imperfeita os jogadores não sabem tudo que ocorreu antes do início da jogada, embora, para esse caso, eles conheçam o lance anterior.

Quadro 2. Formas de divulgação dos certames licitatórios

\begin{tabular}{|l|l|}
\hline Modalidade & Forma de Publicidade \\
\hline Concorrência & $\begin{array}{l}\text { Jornais de circulação municipal, estadual. } \\
\text { DOE (Estado e Município) }\end{array}$ \\
\hline Tomada de Preços & $\begin{array}{l}\text { Jornais de circulação municipal, estadual. } \\
\text { DOE (Estado e Município) }\end{array}$ \\
\hline Convite & Fixação em local apropriado e convite aos interessados. \\
\hline Pregão & $\begin{array}{l}\text { Presencial: } \\
<\mathrm{R} \$ 160,000,00: \text { DOU e Internet. } \\
>\mathrm{R} \$ 160.000,00 \text { e }<\mathrm{R} \$ 650.000,00: \text { DOU, Internet e jornal de } \\
\text { grande circulação local. } \\
>\mathrm{R} \$ 650.000,00: \text { DOU, Internet e Jornal de grande circulação } \\
\text { nacional ou regional. } \\
\text { Eletrônico: } \\
<\mathrm{R} \$ 650,000,00: \text { DOU e Internet. } \\
>\mathrm{R} \$ 650.000,00 \text { e }<\mathrm{R} \$ 1.300 .000,00: \text { DOU, Internet e jornal de } \\
\text { grande circulação. } \\
>\mathrm{R} \$ 1.300 .000,00: \mathrm{DOU}, \text { Internet e Jornal de grande circulação } \\
\text { nacional ou regional. }\end{array}$ \\
\hline
\end{tabular}

A principal etapa da fase externa da licitação trata-se do julgamento das propostas, onde a licitação será adjudicada para o licitante que apresentar o menor preço, no caso de empate ocorre o sorteio. A Lei, art. 43, inciso IV, combinado com art. 48, parágrafo $3^{\circ}$ e art. 24, inciso VII, prever que no caso de todas as propostas serem desclassificadas, por exemplo valor acima do que a administração está disposta a pagar, o prazo será reaberto, 8 dias úteis, para que os licitantes apresentem novas propostas. Mantidas as razões da desclassificação poderá a administração contratar diretamente com um dos licitantes ou com um que não tenha participado do certame. Também, será mostrado, por meio da teoria dos jogos, que essa prerrogativa não impede a prática de conluio.

Por fim, existe o pregão, criado pela Lei $n^{\circ} 10.520 / 2002$, que é a modalidade de licitação para aquisição de bens e serviços comuns (aqueles cujos padrões de desempenho e qualidade possam ser objetivamente definidos pelo edital, por meio de especificações usuais no mercado), independentemente do valor estimado da contratação, 
em que a disputa pelo fornecimento é feita por meio de propostas e lances na forma presencial ou eletrônica. É o inverso do leilão (por isso, o pregão é um tipo de leilão reverso) no qual o licitante vencedor é o que apresenta a maior proposta. As vantagens apresentadas por essa modalidade são transparência, aumento da competitividade, redução dos custos de aquisição, desburocratização e celeridade. A desvantagem do Pregão é a restrição legal de não poder ser usado para contratação de obras e alguns serviços de engenharia.

O pregão representa um avanço no combate às práticas de conluio, visto que no pregão eletrônico para bens/serviços, onde haja muitas empresas, torna-se difícil a articulação entre os licitantes, pois elas não sabem, em nenhuma fase, com quem estão disputando o certame e, como é divulgado e disputado via internet, não se tem idéia de onde é a empresa. Além disso, a fase de lances incentiva a empresa a reduzir os seus preços.

\section{Analisando os instrumentos da Lei de Licitação para evitar as práticas de conluio nas aquisições do setor público.}

Considerando que os agentes respondem a incentivos, então pode-se supor que a eficácia da procedimentos licitatórios depende da sua capacidade em criar incentivos para que os licitantes apresentem propostas verdadeiras. Vale ressaltar que uma proposta verdadeira é aquela que se iguala ao valor que o licitante pode realizar a obra e que lhe assegure a cobertura de todos os seus custos mais uma margem de remuneração compatível com sua atividade. Neste caso não há extração de todo excedente econômico. Os instrumentos que a Lei de Licitação dispõe para que os licitantes apresentem propostas verdadeiras são a ampla divulgação da licitação para ampliar a competividade, a não revelação dos preços estimados, a desclassificação de propostas elevadas e inexeqüíveis e a punição pela cobrança de sobrepreços. A seguir, analisa-se os instrumentos relativos à divulgação e à desclassificação das propostas, pois anteriormente foram analisados os efeitos da não revelação dos preços estimados e a punição pela cobrança de sobrepreços foge dos objetivos do trabalho, que teria que enfatizar os mecanismos da Lei $n^{\circ}$ 8.884/94, que trata de antitrustes.

i) Ampla divulgação do edital de licitação no sentido de ampliar o número de participantes e a competividade.

Supondo que a divulgação aumente o número de participantes e com isso amplie a competição, há incentivo para uma empresa apresentar uma proposta verdadeira? 
Pela Lei das licitações, excluindo o pregão, cada licitante apresenta em envelope lacrado suas propostas em um único lance e aquela mais baixa é considerada a vencedora. Adaptando uma situação de Dixit e Nalebuff (1994), será mostrado o que ocorre numa licitação para uma obra de engenharia.

Quando da elaboração da proposta, um licitante calcula sua proposta em $\mathrm{R} \$ 10$ milhões. Ele não conhece os custos das outras licitantes, mas há razão para acreditar que estão entre $R \$ 5$ e $R \$ 10$ milhões. Uma proposta menor que os custos não é factível, não há como revisar os preços, por isso há probabilidade de inviabilizar o funcionamento da empresa, caso defina um valor abaixo de $R \$ 10$ milhões.

Então o licitante adotará uma estratégia com base nas seguintes condições: i) Supondo que A apresente uma proposta de R 11 milhões, mas ele espera que cinco entre dez propostas fiquem entre $\mathrm{R} \$ 7$ milhões e $\mathrm{R} \$ 10$ milhões, com isso, ele perde e nada adianta cobrar mais; ii) Quatro entre dez propostas sejam superiores a $R \$$ 11 milhões, assim ele poderia ganhar a licitação com uma proposta de $\mathrm{R} \$ 10$ milhões ou de $\mathrm{R} \$ 11$ milhões, sendo que com $\mathrm{R} \$ 11$ milhões ele teria um ganho adicional de $\mathrm{R} \$ 1$ milhão; iii) Há uma chance em dez de haver uma proposta concorrente entre $R \$ 10$ milhões e $R \$$ 11 milhões, neste caso inchar sua proposta significa perder a licitação. Mas sendo verdadeiro e apresentando $\mathrm{R} \$ 10$ milhões, o valor somente paga os custos e um ganho normal (remuneração), por isso, há motivos para apresentar uma proposta maior.

Diante dessas 3 possibilidades, há incentivos para não revelar sua verdadeira proposta e usar uma estratégia com preços superiores a $\mathrm{R} \$ 10$ milhões, ou seja, será uma proposta dominante. Assim pensarão todos os concorrentes e todos irão inflar seus preços.

Qual a solução para o caso, onde mentir é uma estratégia dominante. Seria adotar um formato de licitação, no qual incentivasse os licitantes falarem a verdade. Segundo, Dixit e Nalebuff (1994) deveria ser aplicada uma licitação com o formato de um leilão de segundo preço (Leilão de Vickrey), onde a proposta mais baixa venceria a licitação, mas o vencedor receberia o valor do segundo colocado. Voltando ao caso da licitação acima, se o licitante apresentar a proposta de $R \$ 10.000 .000,00$, ele receberia um valor acima de $R \$ 10.000 .000,00$, caso fosse vencedor. Sendo esse raciocínio implementado por todos, então todos apresentariam propostas verdadeiras e a mais baixa venceria, recebendo o valor da segunda colocada.

Entretanto, esse formato de julgamento não é permitido por lei e pareceria uma solução ineficiente para a administração pública. Veja que se todos licitantes inflam, como no caso anterior, a administração pública pagará um preço maior para a proposta vencedora, 
gerando um custo social (externalidade). Adotando o mecanismo do leilão de segundo preço, ele estaria apenas compensando, pagando ao vencedor a diferença entre a forma anterior de julgar a licitação e a nova pelo segundo preço.

Contudo, como se verifica, o resultado econômico pode ser o mesmo, dependendo do tamanho da compensação. Então, qual seria a motivação para o setor público adotar o leilão de segundo preço? Talvez o fato de não contrariar os princípios constitucionais da eficiência e moralidade e criar uma cultura de transparência nas licitações públicas, onde todos falam a verdade.

Por fim, cabe alertar que o fato da empresa não revelar o seu verdadeiro valor não implica em prática de conluio, representa apenas uma estratégia individual, independentemente de acordo de conluio.

ii) desclassificação de propostas elevadas e inexeqüíveis.

Para os empresários: a cada um é reservada uma estratégia dominante que é praticar o conluio, ${ }^{8}$ independentemente se há ou não intenção da comissão de licitação desclassificar as propostas. Para eles o difícil é formar e coordenar o conluio, feito isso, o conluio se justifica. Antes de se mostrar a ineficácia da sinalização da desclassificação das propostas, cabe verificar um caso onde a cooperação e a formação do conluio leva a resultados melhores que a não cooperação e não conluio. Para ver isso, deve-se simular o seguinte:

a) seja um processo licitatório na modalidade de tomada de preços instaurada por uma prefeitura para contratar uma empresa para execução de uma obra de engenharia. A estimativa da administração para o preço da obra não é divulgada.

b) pela experiência das empresas, elas sabem que os serviços podem ser realizados por $R \$ 300.000,00$, por isso, também sabem que a estimativa da prefeitura deve girar em torno de $\mathrm{R} \$ 350.000,00$.

c) apenas duas empresas se cadastraram dentro do prazo (72 horas antes da abertura das propostas) e estão analisando a possibilidade de adotarem práticas de conluio para obter o maior excedente possível entre os custos efetivos da obra e o valor que a Prefeitura está disposta a pagar para sua realização.

d) sabe-se que devido aos órgãos de controle (tribunais de contas e Controladoria Geral da União) e ministério público, a prefeitura somente pode arriscar contratar a preços de até $\mathrm{R} \$ 400.000,00$ (em torno de $10 \%$ acima do valor estimado).

Analisando por meio de um jogo de conluio, representado na forma normal - ver matriz do jogo a seguir, tem-se que se a empresa

8 Mesmo sabendo se tratar de uma prática ilegal. O fato é que a falta de punição torna o valor esperado da empresa positivo. 
Y adota a prática de conluio e a empresa X não, apresentando uma proposta de $R \$ 400.000,00$, ela perderá a licitação pois a empresa $X$ não cumpriu o acordo. A empresa $\mathrm{X}$ apresentará uma proposta inferior a $\mathrm{R} \$ 400.000,00$, no caso $\mathrm{R} \$ 399.999,99$ para obter o máximo de excedente possível. O mesmo raciocínio vale no caso da empresa X adotar o conluio e a empresa Y não. Mas se houver o conluio, ou seja, ambas cooperarem o conluio extrairá todo excedente de $\mathrm{R} \$ 100.000$, o que permitirá dividi-lo igualmente para os dois e acordarem que a construção cabe a empresa $\mathrm{X}$ agora, para na próxima licitação, na mesma cidade ou em outra cidade, a empresa Y ser a vencedora. Vale ressaltar que há ganhos implícitos adicionais para o vencedor, pois na execução do contrato existe a possibilidade de redução dos custos e obtenção de algo mais - lícita ou ilicitamente. Os dois sabem desse ganho adicional, mas como dependem das ações de cada um, da passividade do contratante e as vezes esse ganho pode não ocorrer, os dois preferem não considerar esse ganho no acordo.

O Conluio seria o equilíbrio do jogo, chamado de Equilíbrio de Nash, (também é eficiente de pareto, tendo em vista que qualquer alteração dessa situação haverá perda para um ou para ambos), pois no caso de não cooperação nesse estágio (nessa licitação) por parte de um, na próxima licitação nenhum dos dois irá adotar prática de conluio, o que levaria os dois a cobrarem $R \$ 350.000,00,{ }^{9}$ levando a licitação ao sorteio. Com o sorteio o valor esperado do payoff de ambos seria de $R \$ 25.000$ (probabilidade de $50 \%$ vezes $R \$$ 50.000 ), o que seria menor que os $R \$ 50.000,00$ obtidos no caso de cooperação entre eles.

O Jogo do Conluio nas Licitações Públicas

\begin{tabular}{|c|l|l|l|}
\cline { 3 - 4 } \multicolumn{2}{c|}{} & \multicolumn{2}{c|}{ Empresa Y } \\
\hline \multirow{2}{*}{ Empresa X } & Conluio & Não Conluio \\
\cline { 2 - 4 } & Não conluio & $50.000 ; 50.000$ & $0 ; 99.000$ \\
\hline
\end{tabular}

Verificado a lógica de formar o conluio, parte-se para mostrar se a ameaça da comissão em desclassificar propostas tem efeito sobre a atuação do conluio.

9 A lógica do valor $\mathrm{R} \$ 350.000,00$ vem da teoria do ponto focal (escolha natural); haveria dois pontos focais $R \$ 300.000,00$ e $R \$ 350.000,00$, como $R \$ 350.000,00$ é maior, elas optariam por esse último valor, trabalhar com o primeiro valor seria muito complicado no caso da prefeitura não honrar com o cronograma de pagamentos. 
Normalmente se percebe nas aquisições e execução de contrato no setor público o seguinte: falhas nas estimativas dos valores licitados, fragilidade na fiscalização da execução dos contratos, poucas empresas dispostas a prestarem serviços para as prefeituras com população abaixo de 100.000 habitantes, devido às práticas irregulares e a dificuldade de recebimento dos valores contratados. Além disso, o mercado já é dividido e ocorre de tudo, empresas montam as propostas dos licitantes e há até subempreita informal para realização do objeto; o licitante vencedor aparece apenas para receber os recursos e dividir com o executor. Mesmo assim é plausível imaginar situações onde haja a possibilidade de existir uma comissão de licitação disposta a desclassificar as propostas consideradas elevadas e orientar o gestor a contratar diretamente sem licitação (com base no art. 24, inciso VII e art. 48 da Lei de Licitação).

Então, a administração pública lança o edital de tomada de preços no jornal de circulação regional para a contratação de empresa para execução de uma obra de engenharia. Há uma sinalização da Comissão de Licitação que irá desclassificar todas as propostas consideradas fora da regra de licitação, pois em licitação anterior foram desclassificadas todas as propostas e usou-se o art. 48 da Lei de Licitação para abertura de prazo para que todos os licitantes apresentassem novas propostas. $\mathrm{O}$ valor estimado pelo Administração não é divulgado, mas pela modalidade de licitação e os anexos do edital que trazem as especificações da obra é possível os licitantes terem uma idéia do valor estimado.

Com base no prazo estipulado pela Lei de Licitação, 3 empresas (X, Y e Z) são cadastradas para o certame, sendo que duas delas sempre participam de licitações naquela cidade e nos municípios próximos. Há um conluio não formalizado entre as duas empresas que aquela licitação seria da empresa $X$, pois em certame anterior venceu a empresa Y. A estrutura de capital das duas empresas são similares. A terceira empresa que se cadastrou no prazo regular quer entrar para participar da licitação, mas sabe que há um conluio entre as empresas X e Y, onde uma protege a outra e dividem o mercado.

Pela experiência das 3 empresas, elas sabem que os serviços podem ser realizados por $\mathrm{R} \$ 300.000,00$, mas apenas o conluio sabe que a estimativa da prefeitura deve girar em torno de $\mathrm{R} \$ 360.000,00$, isto é, há o uso de uma informação privada. Vale lembrar que por razões técnicas e interesses camuflados, que a comissão de licitação não conhecem, as estimativas da área técnica da prefeitura não são boas.

$\mathrm{Na}$ elaboração de sua proposta, a empresa $\mathrm{Z}$ define suas estratégias para disputar e vencer o certame. A sua estrutura de custos não 
permite que cobre menos que $\mathrm{R} \$ 300.000,00$, pois ela não conhece os fiscais de obras da prefeitura e os gestores financeiros para fins de obter vantagens compensatórias na execução do contrato com valor menor que este. Mas ela sabe que os arranjos compensatórios (material de segunda categoria, aditivo ao contrato para serviços que não serão realizados entre outros) na execução do contrato são possíveis para as empresas $\mathrm{X}$ e $\mathrm{Y}$. Ademais, ela sabe que se mergulhar nos preços, abaixo de $\mathrm{R} \$ 300.000,00$, há duas possibilidades: i) sua desclassificação, dependendo do valor estimado pela prefeitura e da manipulação proposital das propostas pelas empresas do conluio); ii) prestar garantias adicionais, caso fique $80 \%$ inferior ao valor da estimativa da prefeitura, o que aumentará os seus custos e o seu prejuízo. ${ }^{10}$

Então a estratégia da empresa $Z$ seria cobrar algo na faixa de $R \$ 300.000,00$ a $R \$ 330.000,00$, o que provavelmente lhe tornaria vencedora do certame. $\mathrm{O}$ conluio sabe que a empresa $\mathrm{Z}$ irá "mergulhar", abaixo de $R \$ 300.000,00$, ou cobrar algo próximo de $R \$$ 330.000 , o que inviabilizaria a sua proposta de obter o máximo possível da prefeitura, que seria algo em torno de $R \$ 40.000,00$ acima do valor estimado, superior a isso, cresce a probabilidade dos órgãos de controle ressalvar a prefeitura ou as propostas serem desclassificadas e a comissão reabrir o prazo de oito dias úteis para reformulação das propostas e, assim, as táticas de conluio das duas empresas serem reveladas de fato para a empresa $Z$.

Em vista disso, o conluio irá dividir o excedente com a empresa $Z$, mas a empresa $Z$ só aceitará algo próximo de $R \$ 30.000,00$ para não entrar no processo licitatório, que seria a diferença entre os seus custos e a margem de lucro anormal que ela poderia obter.

Nos termos de jogo na forma normal, verifica-se a situação apresentada na matriz de payoff a seguir, onde se a empresa $Z$ entra ela pode obter um payoff de $R \$ 30.000,00$ (diferença entre o seu preço verdadeiro e o que a administração aceitaria em pagar). O conluio nada obteria. Mas a empresa $\mathrm{Z}$ teria que mobilizar toda uma estrutura

10 De acordo com o art. 48, inciso II, da Lei no 8.666/93, são manifestadamente inexeqüíveis, no caso de licitações de menor preço para obras e serviços de engenharia, as propostas cujos valores sejam inferiores a $70 \%$ (setenta por cento) do menor dos seguintes valores:

a) média aritmética dos valores das propostas superiores a 50\% (cinqüenta por cento) do valor orçado pela administração, ou

b) valor orçado pela administração.

- Os licitantes cujo valor global da proposta for inferior a $80 \%$ (oitenta por cento) do menor valor a que se referem as duas opções acima, será exigida, para a assinatura do contrato, prestação de garantia adicional igual a diferença entre o valor resultante dos parâmetros citados e o valor da correspondente proposta. 
para executar o contrato e correria o risco da prefeitura não cumprir o cronograma de pagamento. Se o conluio entra e a empresa $Z$ não entra, em vista da proposta do conluio em repartir o excedente, ela ganhará os $\mathrm{R} \$ 30.000,00$ e não terá nenhum custo de mobilização ou risco que é todo do conluio. Assim, o equilíbrio do jogo será (não entra, entra), ficando o conluio com o excedente de $R \$ 70.000,00$, para repartir entre as duas empresas $\mathrm{X}$ e $\mathrm{Y}$ e a empresa $\mathrm{Z}$ com $\mathrm{R} \$$ $30.000,00$. Vale salientar que o conluio não terá incentivo para apresentar uma proposta menor que $R \$ 400.000,00$, pois ele sabe da intenção da prefeitura pagar esse valor, bem como do fato que o valor da proposta da empresa Z será próximo de $R \$ 300.000,00$, por isso, deixar a empresa participar representa um risco muito grande.

Jogo de Barreira em Licitação Pública

\begin{tabular}{|l|l|l|l|}
\cline { 3 - 4 } \multicolumn{2}{c|}{} & \multicolumn{2}{c|}{ Conluio } \\
\cline { 3 - 4 } \multicolumn{2}{c|}{ Entra } & Não entra \\
\hline \multirow{2}{*}{ Empresa Z } & Entra & $30.000 ; 0$ & $30.000 ; 0$ \\
\cline { 2 - 4 } & Não entra & $30.000 ; 70.000$ & $0 ; 0$ \\
\hline
\end{tabular}

Como se verifica, a ameaça de desclassificar pouco ajuda no processo, pois os valores serão os mesmos, o que há é uma redução dos ganhos do conluio, pois este terá que ofertar algo para os entrantes ficarem fora.

Diante disso, pode-se pensar que a solução seria ampliar o máximo a competividade para tornar a repartição do excedente entre as empresas muito pequena a ponto de não ser possível evitar a entrada das empresas, entretanto, não é muito provável a ampliação da competividade devido ao baixo valor envolvido e outras restrições econômicas para as empresas (custos de localização e mobilização, que não se diluem facilmente nos custos variáveis).

$\mathrm{E}$ se os valores orçados fossem menores, sendo no caso um convite e não uma tomada de preços, como evitar o conluio? A situação seria a mesma. Como já dito acima, não há como convidar muitas empresas a ponto de tornar inviável a repartição do excedente (diferença entre valor dos custos efetivos da obra e o valor cobrado pelo vencedor), além disso, haveria estímulo para o surgimento de empresas fabricadas somente para completar o número mínimo de 3 licitantes exigidos pela legislação.

Logicamente, as soluções de cartéis não são estáveis, principalmente quando não há acordos formalizados e punições críveis. Por isso, haverá sempre estímulo para uma empresa do conluio não 
cumprir o trato e apresentar uma proposta dentro das margens da estimativa e vencer a licitação, mas isso somente ocorrerá quando houver uma disputa direta, ou seja, no caso de existirem apenas duas empresas disputando a tomada de preços ou uma concorrência, a entrada de uma ou duas empresas adicionalmente irá estimular a prática de conluio.

E a modalidade Pregão está imune às práticas de conluio?

Inicialmente, vale lembrar que o pregão não se aplica às obras e serviços de engenharia, que representam uma fatia considerável dos gastos públicos. Mas pode-se, resumidamente, analisar duas situações: pregão presencial com muitas empresas e um pregão eletrônico com muitas empresas, ou seja, a divulgação surtindo efeito.

No pregão presencial com muitas empresas participantes, após a abertura das propostas, há uma faixa de corte $^{11}$ e pode ocorrer um limite máximo de empresas participantes dos lances, onde todos os concorrentes se conhecem. Não é permitido o acordo entre as empresas classificadas para os lances, mas nada garante que não tenha havido acordo, visto que a formação do conluio é uma etapa ex ante ao certame, assim as empresas mantém a divisão do mercado. Além disso, pode facilitar os objetivos do conluio, haja vista que, quando da ocorrência dos lances, podem ocorrer duas situações:

1. se forem 3 empresas duas do conluio e uma terceira não. As duas podem manipular a fase de lance;

2. se todas forem participantes do conluio, a redução dos preços via lance pode não ser significativa.

Para o caso do pregão eletrônico, não há como saber quem são os licitantes que estão apresentando lances seqüenciais e a única informação comum é o valor do lance imediatamente anterior. Neste jogo de informação incompleta, a estratégia dominante é baixar o valor até onde for possível cobrir os custos e não sacrificar a rentabilidade. Além disso, a amplitude da divulgação e da participação via internet permite que empresas de diversas localidades participem do certame, o que torna difícil a prática de formação de conluio, devido à dificuldade de coordenação e comunicação entre as empresas. Por isso, no pregão eletrônico com a participação de muitas empresas a probabilidade de conluio fica bastante reduzida.

Com uma simulação bastante simples, verifica-se a seguir se o pregão eletrônico é um mecanismo adequado para fazer o licitante revelar sua informação privada: a administração pública instaura

11 De acordo com o art. $4^{\circ}$, inciso VIII e IX, os lances serão dados pelas empresas que apresentaram propostas iniciais de até $10 \%$ superior a menor proposta. No caso desse critério não permitir um número mínimo de 3 licitantes, abre-se para aqueles, no máximo 3 , que apresentaram as melhores propostas. 
um pregão eletrônico para aquisição de produto na forma da Lei. O licitante 1 na elaboração da sua proposta sabe que a menor proposta terá o direito de iniciar os lances no sistema eletrônico, desde que ela não seja inexequível (muito abaixo do valor estimado da licitação, que somente o pregoeiro conhece), com isso, ele tem incentivo, estratégico, para apresentar uma proposta próxima a sua valorização do bem/serviço, pois a competividade na fase dos lances é que irá reduzir o desvio entre a valoração verdadeira e a que pode gerar excedente. Esse raciocínio será seguido pelos outros licitantes.

$\mathrm{Na}$ fase de lance, supondo que o conluio não exista, o licitante 2, supondo também que ele foi classificado, dará um lance para cobrir a proposta de valor menor apresentada pelo licitante 1, que ofertou a menor proposta inicial, já sabendo que ele se trata de um licitante do tipo que pretende apresentar uma proposta que se iguala a sua valorização do produto e não irá gerar para ele lucro anormal, por isso, o licitante 2 baixará a proposta caso ela não seja inferior a sua proposta verdadeira. Assim os outros farão o mesmo (e sucessivamente), deixando a disputa quando o lance imediatamente anterior for inferior a sua valorização verdadeira.

Então, a disputa ocorrerá até que o valor do último lance seja igual ao valor da proposta verdadeira, principalmente se houver muitos licitantes concorrendo neste estágio. Se o valor do último lance estiver de acordo com o valor estimado ${ }^{12}$ pela administração, haverá a adjudicação da licitação, mostrando que o mecanismo foi capaz de fazer os licitantes revelarem seus tipos e falarem a verdade (chamado na teoria de mecanismo de incentivo compatível).

Se a proposta final estiver acima da estimativa da administração, poderá o pregoeiro negociar com o licitante que apresentou a proposta mais baixa para enfim obter a proposta mais vantajosa para a administração (um tipo de teste ao mecanismo direto usado acima, em que pede ao licitante que revele sua informação privada), caso o licitante aceite baixar ainda mais, ele irá operar com prejuízo e buscará ao longo da execução do contrato compensar esse prejuízo com algum artifício ilegal ou renunciará ao contrato. ${ }^{13}$ Se não baixar,

$12 \mathrm{O}$ valor estimado não necessariamente é o preço reserva, pois a administração aceita um valor acima do estimado, mas esse adicional não pode ser significativo a ponto de gerar muitos esforços para sua complementação orçamentária. Para valores baixos situa-se em torno de $10 \%$, mas para valores elevados não pode passar de $5 \%$.

13 Poderia parecer que o caso seria simétrico a conhecida "maldição dos vencedores" que ocorre nos leilões, onde tende os vencedores a pagarem um preço superior a sua avaliação, devido à concorrência embutida no mecanismo do leilão. Mas no caso de pregão é preferível que a administração pública não extraia excedente do vendedor, pois será uma boa sinalização de futuras práticas indevidas na execução do contrato. 
a administração irá reformular sua estimativa e abrir novo processo de licitação. Como não houve conluio e participaram muitos concorrentes, o fato do insucesso da licitação não se deve ao mecanismo usado, mas a possíveis falhas na estimativa ou nas especificações do produto.

Por fim, vale salientar que, com poucas empresas participando dos pregões presenciais e eletrônicos, principalmente se for decorrente de restrição de mercado e elevados custos de entrada (custos de localização, mobilização, transporte...), a probabilidade de práticas de conluio são razoáveis para manter mercado ou dividi-lo. Um bom exemplo ocorre na área de contratação de serviços de vigilância armada e limpeza e conservação, onde as empresas de um estado não costumam disputar mercado com a de outro estado (talvez um acordo entre os sindicatos estaduais). Neste caso, há um tipo de conluio tácito no qual a ampla divulgação não é suficiente para atrair empresas que tornem os lances informações privadas (um jogo com informações incompletas). ${ }^{14}$

\section{Considerações Finais}

Com base na teoria dos jogos, verificou-se que os incentivos econômicos vislumbrados pelos agentes, incluindo os funcionários públicos que gerenciam o processo licitatório, e a limitada eficácia dos instrumentos licitatórios relativos aos procedimentos de divulgação, julgamento e desclassificação das propostas não evitam a práticas de conluio nas aquisições do setor público, exceto no pregão eletrônico com muitos participantes, onde a probabilidade de práticas de conluio são baixas, pois prevalece uma situação de informações incompletas, tais como o não conhecimento prévio dos licitantes em nenhuma fase dos lances e a amplitude geográfica dos participantes.

Contudo, as práticas de conluio não estão fora do controle da administração pública, visto que é sua competência exigir que as áreas técnicas realizem estimativas dos valores orçados de forma a evitar pagamento de excedentes, com isso, o contrato somente é assinado nessa margem, onde não há excedente para a divisão entre as empresas do conluio. Além disso, pode-se citar outros aspectos que deveriam ser trabalhados para a redução das práticas de conluio, quais sejam:

14 Um caso recente ilustra esse ponto: "O representante do Ministério Público Federal (MPF) no Conselho Administrativo de Defesa Econômica (Cade), pediu a condenação de 19 empresas de vigilância do Rio Grande do Sul e seus dirigentes, além do Sindicato das Empresas de Segurança Privada (Sindesp) e da Associação das Empresas de Vigilância do estado (Assevirgs) por formação de cartel". Fonte: site www.mpf.gov.br, Informe de 30/07/07. 
a) melhoria da percepção política da administração pública realizadora do evento e de sua reputação, no sentido de ser possível executar um contrato e o cronograma de pagamento ser cumprido;

b) ampliação da competitividade via divulgação do edital na internet;

c) permissão do uso da modalidade de pregão para contrato de obras e serviços de engenharia possíveis de serem caracterizado de forma comum e padronizada;

d) atuação agressiva da polícia, ministério público, controle interno e externo e do poder judiciário na aplicação da Lei de Licitação e da Lei Antitruste no que tange às práticas de cartel;

e) gerenciamento do contrato via monitoramento dos serviços realizados, com atuação adequada dos fiscais dos contratos.

\section{Referências Bibliográficas}

BIERMAM, H. S.; FERNANDEZ, L. Game Theory - with Economic Applications. AddisonWesley Publishing Company, 1998.

DIXIT, A. K.; NALEBUFF, B. J. Pensando Estrategicamente: a vantagem competitiva nos negócios, na política e no dia-a-dia. São Paulo: Atlas, 1994.

FERNANDES, J. U. J. A licitação e os Cartéis. Disponível em: <www.escritorioonline.com.br>. Acesso em: 16/01/01

FLORES, G. A. Cartel: teoria econômica e a prática antitruste no Brasil. 2006. Tese de Mestrado, UFF/RJ.

GIBBONS, R. Game Theory For Applied Economists. Princeton University Press, 1992.

KLITGARD, R. A Corrupção Sob Controle. Rio de Janeiro: Jorge Zahar Ed., 1994.

LEVITT, S. D.; DUBNER, S. J. Freakonomics: o lado oculto e inesperado de tudo que nos afeta. Rio de Janeiro: Editora Campus, 2005.

MAS-COLLEL, A.; WHINSTON, M.D.; GREEN, J. R. Microeconomic Theory. New York: Oxford University Press, 1995.

PINDICK, R. S.; RUBINFELD, D. L. Microeconomia. São Paulo: 5. ed., Prentice Hall. 2002.

SILVA, G. P. Os Cártéis, a Licitação e a Teoria dos Jogos. Disponível em: <http// jus2.uol.com.br/doutrina/texto.asp?id=1980>.

TIROLE, J. The Theory of Industrial Organization. Cambridge: MIT Press, 1988.

VARIAN, H. R. Intermediate Microeconomics: a Modern Approach. WW Norton $\mathcal{E}$ Company. Fourth Edition. 1996.

LEGISLAÇÃO BRASILEIRA. Disponível em: http// www.planalto.gov.br. 